\title{
Lifestyle Counseling for Medication Adherence in Glaucoma
}

\author{
Sandy Kim' \\ Betty Tong' \\ Jessica Lee' \\ Darara Borodge' \\ Karanjit Kooner ${ }^{1,2}$ \\ 'Department of Ophthalmology, \\ University of Texas Southwestern \\ Medical Center, Dallas, TX, USA; \\ ${ }^{2}$ Department of Ophthalmology, \\ Veterans Affairs North Texas Health \\ Care System, Dallas, TX, USA
}

Background: Medication adherence in glaucoma patients remains sub-par despite proven benefits of regular administration. The objective was to analyze medication adherence before and after lifestyle counseling in patients with ocular hypertension (OHT) or primary openangle glaucoma (POAG) (mild, moderate, severe).

Methods: Prospective cohort study from May to July 2018 at a single academic center. From 391 consecutive records, 247 were excluded based on exclusion criteria with 28 patients not meeting inclusion criteria resulting in the final sample of 116 patients ( 33 had OHT, 83 had POAG - 28 mild, 39 moderate, 16 severe). Scripted lifestyle counseling focusing on diet, exercise, vitamin intake, stress management, and medication adherence was administered by a team of trained medical students. Primary outcome measure was selfreported medication adherence, defined as not missing an eye drop administration in the past month. A 2-3 week follow-up with scripted telephone survey assessing medication adherence, diet, and exercise was collected.

Results: At baseline, in 116 patients, 59.5\% were adherent to their medication with a breakdown of $42.4 \%$ OHT, $64.3 \%$ mild, $66.7 \%$ moderate, and $68.7 \%$ severe and an increasing trend in medication adherence was found across increasing disease severity $(\mathrm{p}=0.055)$. Of the $76(65.5 \%)$ patients reached for follow-up, $17(22.4 \%)$ became adherent following lifestyle counseling ( $\mathrm{p}=0.02$ ) increasing overall adherence to $78.9 \%$ from $62.5 \%$. Conclusion: In our study, comprehensive lifestyle counseling succeeded in increasing medication adherence in patients with OHT and POAG.

Keywords: glaucoma, lifestyle counseling, medication adherence

\section{Introduction}

Despite effective medical and surgical therapy, glaucoma is still a leading cause of irreversible blindness worldwide. ${ }^{1}$ This trend is exacerbated by non-adherence to medication regimens requiring daily eye drop administration to lower intraocular pressure (IOP) and prevent disease progression. Research has shown that patients who administer $80 \%$ or more of their prescribed eye drops have an $86 \%$ reduction in their odds of having moderate or severe visual field defects. ${ }^{2}$ A recent study by Newman-Casey and colleagues confirmed a dose-dependent relationship between medication non-adherence and visual field loss over a period of 8 years with patients who reported not missing doses having similar annual visual field loss as those with stable glaucoma. ${ }^{3}$

Despite the benefits of medication adherence, various studies have found that

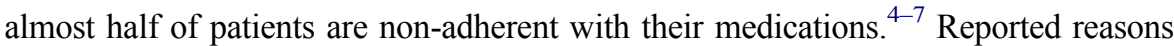
include forgetfulness, ${ }^{8}$ cost, lack of knowledge surrounding the glaucoma disease
Correspondence: Karanjit Kooner Department of Ophthalmology, University of Texas Southwestern Medica Center, 5323 Harry Hines Blvd., Dallas,

TX, 75390-9057, USA

Tel $+1214648-4733$

Fax + I $214648-2270$

Email Karanjit.

Kooner@UTSouthwestern.edu 
process or purpose of medical therapy, 9,10 and provider's lack of communication regarding proper medication administration and adherence during clinic visits. ${ }^{11}$ The chronic and asymptomatic nature of vision loss coupled with preventive rather than curative properties of glaucoma medication make it difficult for patients to adhere to a medication regimen they cannot see the direct benefits of.

Most studies analyzing the effects of educational interventions on medication adherence have designed interventions focused on eye drop administration technique and patient provider communication by showing patients instructional videos for eye drop administration, ${ }^{12}$ videotaping and transcribing clinic visits, ${ }^{13,14}$ and assigning trained personnel to counsel patients. ${ }^{15}$ Interventions built on patient education and motivational interviewing are hypothesized to have improved glaucoma medication adherence by increasing patient confidence in following medication regimens ${ }^{14,16-20}$. Carpenter and colleagues found that provider education regarding medication adherence was associated with improved IOP at an eightmonth follow-up. ${ }^{14}$ Despite the evidence that these interventions are successful in improving medication adherence, there remains a high proportion of medication non-adherence in glaucoma patients indicating that educating patients on proper administration and regimen may not be the only limiting factor.

Fewer studies have focused on or incorporated lifestyle counseling in glaucoma despite evidence of benefit in similar "silent" diseases, such as diabetes and hypertension. Interventions focused on long-term behavioral control, such as diet, exercise, and weight loss, have shown glucose and blood pressure levels under control for as long as two years. ${ }^{21-27}$ While there exist few epidemiological studies on lifestyle risk factors for POAG, some research has shown evidence that certain lifestyle activities such as exercise, diet, vitamin intake, and smoking affect glaucoma disease onset and progression. ${ }^{28}$

Given these findings, our study aimed to assess the effects of a more holistic, lifestyle-centered counseling on medication adherence. We hypothesized that lifestylebased sessions would improve adherence to medication regimens by motivating patients to overall live healthier lifestyles.

\section{Methods}

\section{Study Design}

In this prospective cohort study, we interviewed 391 consecutive patients and selected 116 eligible patients at the
University of Texas Southwestern (UTSW) Medical Center Eye clinic from May to July 2018, from which we obtained baseline data. During the single face-to-face counseling session, patients were counselled on lifestyle habits (diet, exercise, vitamin supplements, stress) and medication adherence. They were sent home with printed educational materials and interviewed at 2-3 weeks follow-up via phone call regarding changes made to lifestyle and medication adherence. Information about the purpose of the study and verbal consent was obtained from patients prior to counseling. A team of 3 trained medical students who followed a standardized script provided counseling in clinic. The same medical student research team conducted similarly scripted phone interviews to follow-up with patients after counseling and obtain post-intervention data. The UTSW Institutional Review Board approved our protocol and verbal consent process, and we followed the tenets of the United States Health Insurance Portability and Accountability Act of 1996 (HIPAA) and the Declaration of Helsinki for research involving human subjects.

\section{Lifestyle Counseling Intervention}

Prior to their office visit, eligible patients were given lifestyle counseling. The session consisted of first obtaining baseline data unavailable in the EMR (education, employment status, family history of glaucoma, stress level, medication adherence). Then, a comprehensive lifestyle counseling was conducted by going over a pamphlet with pictures of recommended fruits and vegetables in correct portion sizes, stress control strategies, exercise frequency and duration, OTC vitamins, and tips for medication adherence. These counseling categories were selected based on data that these variables may affect glaucoma disease onset and progression. ${ }^{28}$ The script for the intervention is shown in Table 1.

\section{Patient Selection}

Eligibility criteria included a diagnosis of OHT or mild/ moderate/severe POAG and prescription of at least one glaucoma medication. Patients with OHT were included if they had no visual field (VF) defects and at least one of the following: IOP $\geq 21 \mathrm{mmHg}$, suspicious optic discs, antiglaucoma medication prescription. Patients were diagnosed with POAG if they had suspicious optic discs, open iridocorneal angles confirmed by gonioscopy, and VF defects characteristic of glaucoma. Suspicious optic discs were defined as noticeable cupping, neuroretinal rim 
Table I Lifestyle Counseling Intervention

\begin{tabular}{|c|c|}
\hline Variable & Counseling Script \\
\hline $\begin{array}{l}\text { Medication } \\
\text { Adherence }\end{array}$ & $\begin{array}{l}\text { Continued encouragement of daily drop use } \\
\text { Use drops before } 7 \text { AM if possible } \\
\text { Use drops the same time everyday } \\
\text { Wait at least } 5 \text { minutes between drops } \\
\text { Match the timing of drops with meals, with use by } \\
\text { 8-9 PM }\end{array}$ \\
\hline Diet & $\begin{array}{l}\text { Do you eat a balanced diet daily? } \\
\text { Do you eat processed foods daily? } \\
\text { Do you eat fast food daily? } \\
\text { How many servings ( } / 2 \text { cup) of fruit/vegetables } \\
\text { do you eat per day? }\end{array}$ \\
\hline Vitamin & What vitamins do you take? \\
\hline Exercise & $\begin{array}{l}\text { Do you exercise at least } 30 \mathrm{~min} / \text { day for } \geq 5 \text { days } \\
\text { a week? }\end{array}$ \\
\hline Stress & $\begin{array}{l}\text { Suggested stress reducing measures: } \\
\text { Exercise } \\
\text { Yoga } \\
\text { Meditation, deep breathing } \\
\text { Improving sleep patterns } \\
\text { Plant based diet (reducing processed, animal- } \\
\text { based products) }\end{array}$ \\
\hline
\end{tabular}

thinning or notching, or a retinal nerve fiber layer (RNFL) defect characteristic of glaucoma. Patients with POAG were separated into mild, moderate, or severe, based on their VF mean deviation (MD) of less than $-6 \mathrm{~dB}$ and -12 $\mathrm{dB}$ and greater than $-12 \mathrm{~dB}$, respectively, using the modified Hodapp-Parrish-Anderson classification. ${ }^{29}$ Exclusion criteria included age less than 18 years, secondary glaucoma, acute angle closure glaucoma, recent glaucoma or cataract surgery, significantly restricted mobility, and memory/cognitive impairment (Figure 1).

\section{Data Collection}

Data collected included age, race, sex, education, employment, body mass index (BMI), family history of glaucoma, type of glaucoma, number of prescribed glaucoma medications, and information on missed drops. Patients were also questioned on reasons for missing drops such as forgetfulness, cost, side effects, and physical difficulties.

The validated perceived stress scale was used to measure patient stress scores. ${ }^{30}$ Patients were asked 10 questions that addressed how often they felt a negative emotion in the past month, such as anxiety, inability to control important things in their life, and anger because of things that had happened outside of their control. Possible responses were never (0), almost never (1), sometimes (2), fairly often (3), and very often (4). Answers were summed into a perceived stress score from 0 to 40 .

The 2-3-week follow-up phone interview asked about changes made to the patients' diet, vitamin intake, exercise, stress level, and medication adherence in response to the previous lifestyle counseling session. Responses were categorized into more than before, same as before, and less than before. This interview was primarily for data collection and was not a second intervention.

\section{Variables}

Medication adherence was defined as whether patients had ever missed their drops in the past month and dichotomized into a yes/no variable. Age was left a continuous variable, while all other variables were coded as categorical variables. Sex was dichotomized into male and female. Given sample size restrictions, certain variables had to be stratified into larger groups, such as race (white, black, other), education (high school or less, college or more), employment (unemployed, employed), and stress level (mild stress, moderate stress and high stress). For stress level, a perceived stress score from 0 to 13 was defined as mild stress, 14-26 as moderate stress, and 2740 as high stress. No patient fell within the high-stress category (Table 2).

\section{Statistical Analysis}

Study data were collected and managed using REDCap electronic data capture tools hosted at $\mathrm{UTSW}^{31}$ and de-identified according to IRB protocol. From an exported Excel data file, one randomized eye per patient was selected for analysis using the Microsoft Excel $^{32}$ (Microsoft Corporation in Redmond, Washington) random number function. $\mathrm{R}$ software ( $\mathrm{R}$ foundation in Vienna, Austria) was used for the following statistical analyses. ${ }^{33}$ First, a contingency table was calculated for Fisher's Exact Test to analyze disease group differences in medication adherence at baseline. A Cochrane Armitage Trend Test was then performed using this contingency table to analyze the trend in adherence across glaucoma disease groups. A second contingency table was tabulated to analyze differences in medication adherence between baseline and follow-up. Finally, predictive factors (age, race, sex, education, employment, BMI, family history of glaucoma, stress level, disease category, and number of prescribed medications) of medication adherence were 


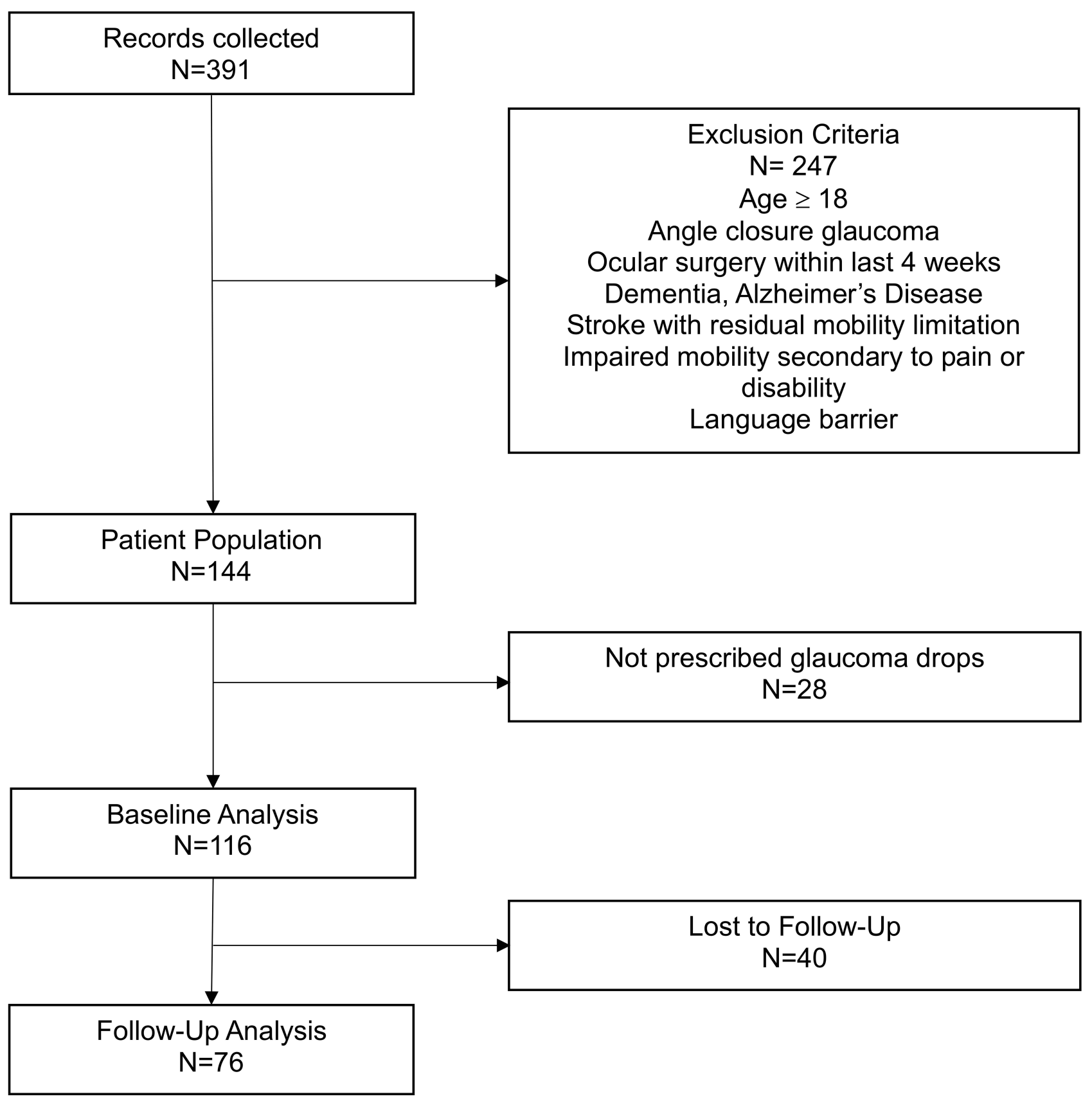

Figure I Study flow diagram.

analyzed using multivariate logistic regression. An alpha value of 0.05 was used as the cutoff for statistical significance.

\section{Results}

\section{Patient Demographics}

Of 116 patients, there were 33 patients with OHT and 83 patients with POAG (28 mild, 39 moderate, and 16 severe). At baseline, $40.5 \%$ of patients were found to be non-adherent with their medication regimen. Mean age was 67.6 years $\pm 11.2,43.1 \%$ were white, $48.3 \%$ male, $70.7 \%$ college educated, and $50.9 \%$ employed. Mean BMI was $28.3 \pm 6.4,62.1 \%$ had a family history of glaucoma, $70.7 \%$ were found to have mild stress, and $61.2 \%$ had 2 or more prescribed glaucoma medications. There were no statistically significant differences in age, race, sex, education, employment, mean BMI, family history of glaucoma, stress level, disease category, and number of prescribed medications between non-adherent and adherent patients (Table 3). 
Table 2 Data Collection

\begin{tabular}{|c|c|c|}
\hline Variable & Question & Analysis \\
\hline Age & Retrieved from EMR & Mean $(y r)$ \\
\hline Race & Retrieved from EMR & $\begin{array}{l}\text { White, } \\
\text { Black, Other }\end{array}$ \\
\hline Sex & Retrieved from EMR & $\begin{array}{l}\text { Male } \\
\text { Female }\end{array}$ \\
\hline Education & Highest level of education? & $\begin{array}{l}\text { High School } \\
\text { or Less } \\
\text { College or } \\
\text { More }\end{array}$ \\
\hline Employment Status & $\begin{array}{l}\text { Employed/Unemployed/ } \\
\text { Retired/Disability/Homemaker }\end{array}$ & $\begin{array}{l}\text { Unemployed } \\
\text { Employed }\end{array}$ \\
\hline $\begin{array}{l}\text { Body Mass Index } \\
\text { (BMI) }\end{array}$ & Retrieved from EMR & $\begin{array}{l}\text { Mean }(\mathrm{kg} / \\
\left.\mathrm{m}^{2}\right)\end{array}$ \\
\hline $\begin{array}{l}\text { Family History of } \\
\text { Glaucoma }\end{array}$ & $\begin{array}{l}\text { Any family histories were } \\
\text { noted }\end{array}$ & $\begin{array}{l}\text { No } \\
\text { Yes }\end{array}$ \\
\hline Stress Level & Perceived Stress Scale (ref) & $\begin{array}{l}\text { Mild } \\
\text { Moderate } \\
\text { Severe }\end{array}$ \\
\hline Disease Category & $\begin{array}{l}\text { Retrieved from EMR, one eye } \\
\text { randomized }\end{array}$ & $\begin{array}{l}\text { OHT } \\
\text { Mild POAG } \\
\text { Moderate } \\
\text { POAG } \\
\text { Severe } \\
\text { POAG }\end{array}$ \\
\hline $\begin{array}{l}\text { Number of } \\
\text { Prescribed } \\
\text { Medications }\end{array}$ & Retrieved from EMR & $\begin{array}{l}1 \\
2 \\
3 \text { or more }\end{array}$ \\
\hline $\begin{array}{l}\text { Medication } \\
\text { Adherence }\end{array}$ & Does patient miss drops? & $\begin{array}{l}\text { Yes - } \\
\text { nonadherent } \\
\text { No- } \\
\text { Adherent }\end{array}$ \\
\hline
\end{tabular}

\section{Baseline}

The Fisher's Exact Test revealed no significant differences in medication adherence between glaucoma disease categories (Table 4). However, the Cochrane Armitage Trend test did reveal that there was a slightly significant trend of increasing medication adherence as disease status progressed $(\mathrm{p}=0.055)$.

The multivariate logistic regression with dichotomous outcome of medication adherence showed that compared to patients with OHT, patients with moderate POAG were
Table 3 Characteristics of Patient Population

\begin{tabular}{|c|c|c|c|}
\hline \multirow[t]{2}{*}{ Variables } & Nonadherent & Adherent & \multirow[t]{2}{*}{$\mathbf{p}$} \\
\hline & $\mathrm{N}=47(40.5 \%)$ & $\begin{array}{l}N=69 \\
(59.5 \%)\end{array}$ & \\
\hline Age, yr mean & $68 \pm 11.7$ & $67 \pm 10.9$ & 0.77 \\
\hline \multicolumn{4}{|l|}{ Race } \\
\hline White & $17(36.2)$ & $33(47.8)$ & 0.46 \\
\hline Black & $19(40.4)$ & $23(33.3)$ & \\
\hline Other & II (23.4) & $13(18.8)$ & \\
\hline \multicolumn{4}{|l|}{ Sex } \\
\hline Male & $23(48.9)$ & $33(48.5)$ & 1.00 \\
\hline Female & $24(51.1)$ & $35(51.5)$ & \\
\hline \multicolumn{4}{|l|}{ Education } \\
\hline High School or Less & $13(27.7)$ & $21(30.4)$ & 0.91 \\
\hline College or More & $34(72.3)$ & $48(69.6)$ & \\
\hline \multicolumn{4}{|l|}{ Employment } \\
\hline Unemployed & $21(44.7)$ & $36(52.2)$ & 0.55 \\
\hline Employed & $26(55.3)$ & $33(47.8)$ & \\
\hline BMI, $\mathrm{kg} / \mathrm{m}^{2}$ mean & $28 \pm 5.7$ & $29 \pm 6.9$ & 0.31 \\
\hline \multicolumn{4}{|l|}{ Family $\mathrm{Hx}$ of Glaucoma } \\
\hline No & $20(42.6)$ & $24(34.8)$ & 0.51 \\
\hline Yes & $27(57.4)$ & $45(65.2)$ & \\
\hline \multicolumn{4}{|l|}{ Stress Level } \\
\hline Mild & $36(78.3)$ & $46(73.0)$ & 0.69 \\
\hline Moderate & $10(21.7)$ & $17(27.0)$ & \\
\hline \multicolumn{4}{|l|}{ Disease category } \\
\hline OHT & $19(40.4)$ & $14(20.3)$ & 0.13 \\
\hline Mild POAG & $10(2 \mid .3)$ & $18(26.1)$ & \\
\hline Moderate POAG & $13(27.7)$ & $26(37.7)$ & \\
\hline Severe POAG & $5(10.6)$ & II (I5.9) & \\
\hline \multicolumn{4}{|l|}{ Number of Prescribed } \\
\hline \multicolumn{4}{|l|}{ Medications } \\
\hline 1 & I8 (38.3) & $27(39.1)$ & 0.95 \\
\hline 2 & $17(36.2)$ & $23(33.3)$ & \\
\hline 3 or more & $12(25.5)$ & $19(27.5)$ & \\
\hline
\end{tabular}

Abbreviations: BMI, body mass index; POAG, primary open angle glaucoma; $\mathrm{OHT}$, ocular hypertension.

4.14 times more likely ( $95 \%$ CI $1.33-14.24$ ) to be adherent to their medication regimen, while patients with severe POAG were 6.42 times more likely $(95 \%$ CI 1.28-37.67). These findings, although significant, did have wide confidence intervals. Other factors, such as age, race, sex, education, employment, BMI, family history, stress level, and number of prescribed medications, did not influence the odds of medication adherence (Table 5). 
Table 4 Fisher's Exact Test for Independence Adherence by Disease Category

\begin{tabular}{|c|c|c|c|c|c|}
\hline \multicolumn{2}{|c|}{$\begin{array}{l}\text { Contingency } \\
\text { Table }\end{array}$} & & & & \\
\hline \multirow{2}{*}{\multicolumn{2}{|c|}{ Variable }} & OHT & $\begin{array}{c}\text { Mild } \\
\text { POAG }\end{array}$ & $\begin{array}{c}\text { Moderate } \\
\text { POAG }\end{array}$ & $\begin{array}{l}\text { Severe } \\
\text { POAG }\end{array}$ \\
\hline & & $\begin{array}{c}N=33 \\
(\%)\end{array}$ & $\begin{array}{c}N=28 \\
(\%)\end{array}$ & $\mathrm{N}=39(\%)$ & $N=16$ (\%) \\
\hline \multirow[t]{2}{*}{ Adherence } & Yes & $\begin{array}{c}14 \\
(42.4)\end{array}$ & $\begin{array}{c}18 \\
(64.3)\end{array}$ & $26(66.7)$ & II (68.7) \\
\hline & No & $\begin{array}{c}19 \\
(57.6)\end{array}$ & $\begin{array}{c}10 \\
(35.7)\end{array}$ & $13(33.3)$ & $5(3 \mid .3)$ \\
\hline \multicolumn{2}{|c|}{$\begin{array}{l}\text { Fisher's Exact } \\
\text { Test }\end{array}$} & \multicolumn{4}{|c|}{$\mathrm{P}$-value $=0.142$} \\
\hline \multicolumn{2}{|c|}{$\begin{array}{l}\text { Cochran } \\
\text { Armitage Trend } \\
\text { Test }\end{array}$} & \multicolumn{4}{|c|}{$\begin{array}{l}\text { z-statistic }=-1.916 \\
\mathrm{p} \text {-value }=0.055\end{array}$} \\
\hline
\end{tabular}

Abbreviations: OHT, ocular hypertension; POAG, primary open angle glaucoma.

\section{Follow-Up}

Of the 116 patients, $76(65.5 \%)$ were reached by phone call at the 2-3 weeks post intervention. At baseline $62.2 \%$ of the followed population reported adherence while after intervention $78.9 \%$ reported medication adherence, an increase of $16.7 \%$. In the population, we lost to followup (40 patients), $52.5 \%$ reported medication adherence and demographics were similar to followed patients. A contingency table calculating the number adherent at baseline and at second encounter was created, and McNemar's Test was performed (Table 6). Among 76 patients, 17 (22.4\%) patients who were initially not adherent at baseline became adherent to their medication regimens following lifestyle counseling $(\mathrm{p}=0.017)$. Furthermore, of those whom follow-up was obtained, $29 \%$ reported improved diet while $68 \%$ remained the same and $24 \%$ reported improved exercise while $67 \%$ remained the same. In our sample, we observed that almost one-third of our patients improved their diet and exercise habits following lifestyle counseling.

\section{Discussion}

In this prospective study, we found that comprehensive lifestyle counseling inclusive of diet, exercise, vitamin intake, stress level, and medication adherence was successful in improving glaucoma medication adherence at a $2-3$ week follow up $(62.5 \%$ adherent at baseline and
Table 5 Logistic Regression Results

\begin{tabular}{|c|c|c|c|}
\hline & \multicolumn{3}{|c|}{ Adherence } \\
\hline & \multirow[t]{2}{*}{ OR } & \multicolumn{2}{|c|}{$95 \% \mathrm{Cl}$} \\
\hline$N=107^{*}$ & & & \\
\hline Age, yr & 0.97 & $(0.92$ & I.0I) \\
\hline Race, Other ${ }^{\dagger}$ & & & \\
\hline White & 2.10 & $(0.69$ & 6.54) \\
\hline Black & 1.05 & $(0.32$ & 3.46) \\
\hline Sex, Male ${ }^{\dagger}$ & & & \\
\hline Female & 0.96 & $(0.38$ & $2.41)$ \\
\hline Education, High School or Less ${ }^{\dagger}$ & & & \\
\hline College or more & 0.79 & $(0.28$ & $2.15)$ \\
\hline Employment, Unemployed ${ }^{\dagger}$ & & & \\
\hline Employed & 0.68 & $(0.25$ & I.82) \\
\hline BMI, $\mathrm{kg} / \mathrm{m}^{2}$ & 1.05 & $(0.98$ & I.13) \\
\hline Family $\mathrm{Hx}, \mathrm{No} \mathrm{Hx}$ of Glaucoma ${ }^{\dagger}$ & & & \\
\hline Hx of Glaucoma & 1.43 & $(0.59$, & $3.50)$ \\
\hline Stress Level, Mild Stress ${ }^{\dagger}$ & & & \\
\hline Moderate Stress & 1.53 & $(0.56$ & 4.35) \\
\hline Disease Category, $\mathrm{OHT}^{\dagger}$ & & & \\
\hline Mild POAG & 2.38 & $(0.76$ & 7.86) \\
\hline Moderate POAG & 4.14 & $(1.33$ & 14.24) \\
\hline Severe POAG & 6.42 & $(1.28$ & 37.67) \\
\hline Number of Prescribed medications, $\mathrm{I}^{\dagger}$ & & & \\
\hline 2 medications & 0.66 & $(0.23$ & I.82) \\
\hline 3 or more medications & 0.53 & (0.15, & I.75) \\
\hline
\end{tabular}

Notes: $*_{n}=9$ with missing covariate values were dropped from analysis. ${ }^{\dagger}$ Reference category

Abbreviations: OR, adjusted odds ratio; OHT, ocular hypertension; POAG, primary open angle glaucoma; BMI, body mass index; $\mathrm{Hx}$, history.

$78.9 \%$ adherent at follow-up). Almost one-quarter of the patients reached for follow-up who were previously nonadherent became adherent following lifestyle counseling. The significant trend between more progressive glaucoma disease status and medication adherence and an increased odds of adherence for patients with moderate and severe POAG compared to patients with OHT may indicate the benefits of counseling on medication adherence. It is possible that these patients may be followed more closely in clinic and thus receive more tailored counseling from the physician or that these patients who have decreased vision status secondary to their glaucoma progression are more cognizant of adverse outcomes associated with a lack of medication adherence. Furthermore, counseling that incorporated diet, exercise, and stress control strategies may 
Table 6 McNemar's Test for Follow-Up Adherence

\begin{tabular}{|l|c|c|c|}
\hline Contingency Table & \multicolumn{2}{|c|}{} & \multicolumn{2}{|c|}{$\begin{array}{c}\text { Adherence at } \\
\text { Second } \\
\text { Encounter N=76 } \\
\text { (\%) }\end{array}$} \\
\hline & \multicolumn{2}{|c|}{ Yes } & No \\
\hline $\begin{array}{l}\text { Adherence at First Encounter N=76 } \\
\text { (\%) }\end{array}$ & Yes & $\begin{array}{c}43 \\
(56.6)\end{array}$ & $5(6.6)$ \\
\cline { 2 - 4 } & No & $\begin{array}{c}17 \\
(22.4)\end{array}$ & $\begin{array}{c}\text { (II } \\
\text { Became Noncompliant }\end{array}$ \\
\hline Became Compliant & \multicolumn{2}{|c|}{$5(6.6 \%)$} \\
\hline Odds Ratio & \multicolumn{2}{|c|}{\begin{tabular}{c}
$17(22.4 \%)$ \\
\hline p-value
\end{tabular}} & \multicolumn{2}{|c|}{0.017} \\
\hline
\end{tabular}

have helped patients to become motivated to pursue more healthier lifestyles overall. Being able to see and feel the effects of a healthier lifestyle combined with the providers' attention to their overall health status may be a powerful motivation for patients to adhere to their medication regimen.

Contrary to what is reported in the literature, our study did not find a significant difference in medication adherence based on age, ${ }^{8,34}$ race, ${ }^{35}$ and education. ${ }^{36}$ In our sample, we did not find these predictive factors of nonadherence. Moreover, we did not find high stress levels to be a predictor of low adherence, although previous studies have found depression and living alone to be significant risk factors. ${ }^{37}$ It is possible that our small sample size masked differences. Additionally, our population was drawn from a single academic center and the patients of one faculty physician which may also have affected our findings.

Recent studies have found several lifestyle modifiable factors limit glaucoma disease progression, such as smoking cessation, exercise, limit of caffeine intake, control of diabetes, consumption of antioxidants, balanced diet of fruits and vegetables, and maintenance of a healthy weight. $^{28,38-40}$ Given the multifactorial causes of glaucoma, a comprehensive approach that focuses on other aspects of glaucoma disease management including eating a healthy diet, exercising, managing stress, and supplementing with vitamins may not only improve medication adherence but also ultimately lead to the clinically important outcome of improved IOP.

This study was not without limitations. Self-reported responses to medication adherence were used as our primary outcome, a measure that has been documented previously as being often overestimated. ${ }^{41}$ Patients were aware they were part of a research study analyzing the effects of lifestyle counseling on glaucoma. This most likely contributed to the Hawthorne effect, ${ }^{42}$ artificially increasing adherence to medication regimens. Our sample size was limited due to an extensive exclusion criteria and time restrictions for primary data collection, impacting the generalizability of our results. Additionally, we were not able to assess IOP at follow-up as it was conducted over the phone and not in clinic. Furthermore, due to our research team being primarily composed of medical students with limited schedules, we were not able to assess the effects of a more continuous intervention with repeated lifestyle counseling sessions and long-term follow-up. Pursuing a more long-term follow-up rather than 2-3 weeks would have elucidated more information regarding the endurance of medication adherence improvement. ${ }^{11}$

Despite these limitations, our study proved that lifestyle counseling sessions significantly improved glaucoma medication adherence and opens the door for a more holistic approach towards patient counseling. Many ophthalmologists and glaucoma specialists are already counseling their patients regarding lifestyle choices. This study is the first study to provide statistical evidence that lifestyle counseling increased medication adherence. Current epidemiological studies have attempted to stratify the risk for glaucoma onset by analyzing the effects of certain lifestyle risk factors such as smoking, diet, and exercise on the IOP of healthy subjects. $^{28}$ More research is needed on whether lifestyle changes in conjunction with medication adherence can improve or prevent progression of glaucoma in patients who are already suffering from the condition.

Lifestyle counseling sessions inclusive of diet, exercise, stress, vitamin intake, and medication improved medication adherence in glaucoma patients. This study was limited by self-reported outcome measures and sample size constraints. Future studies should analyze whether lifestyle counseling improves medication adherence in a larger multi-center study population as well as long-term clinical outcomes, such as continued medication adherence and improved IOP. 


\section{Acknowledgments}

Special thanks to Beverley Adams-Huet and M.S, Xilong $\mathrm{Li}, \mathrm{Ph} . \mathrm{D}$. for providing statistical analysis and to Drs. Andrew Pazandak, Ghadeer Al-Humimat, and Derek Fung for reviewing our manuscript.

\section{Funding}

Supported in part by an unrestricted grant from the Research to Prevent Blindness, New York, NY: Visual Sciences Core Grant EY020799, NIH CTSA Grant UL1TR001105 and CTSA NIH Grant UL1-RR024982.

\section{Disclosure}

The authors report no conflicts of interest in this work.

\section{References}

1. Newman-Casey P, Anne D, Megan RAL. Systematic review of educational interventions to improve glaucoma medication adherence: an update in 2015. Expert Rev Ophthalmol. 2016;11(1):5-20. doi:10.1586/17469899.2016.1134318

2. Sleath B, Blalock S, Covert D, et al. The relationship between glaucoma medication adherence, eye drop technique, and visual field defect severity. Ophthalmology. 2011;118(12):2398-2402. doi:10.1016/j.ophtha.2011.05.013

3. Newman-Casey PA, Niziol LM, Gillespie BW, Janz NK, Lichter PR, Musch DC. The association between medication adherence and visual field progression in the Collaborative Initial Glaucoma Treatment Study. Ophthalmology. 2020;127(4):477-483. doi:10.1016/j. ophtha.2019.10.022

4. Schwartz GF, Quigley HA. Adherence and persistence with glaucoma therapy. Surv Ophthalmol. 2008;53(Supp11):S57-68. doi:10.1016/j. survophthal.2008.08.002

5. Reardon G, Kotak S, Schwartz GF. Objective assessment of compliance and persistence among patients treated for glaucoma and ocular hypertension: a systematic review. Patient Prefer Adherence. 2011;5:441-463. doi:10.2147/PPA.S23780

6. Olthoff CMG, Schouten JSAG, van de Borne BW, Webers CAB. Noncompliance with ocular hypotensive treatment in patients with glaucoma or ocular hypertension an evidence-based review. Ophthalmology. 2005;112(6):953-961. doi:10.1016/j. ophtha.2004.12.035

7. Newman-Casey PA, Blachley T, Lee PP, Heisler M, Farris KB, Stein JD. Patterns of glaucoma medication adherence over four years of follow-up. Ophthalmology. 2015;122(10):2010-2021. doi:10.1016/ j.ophtha.2015.06.039

8. Newman-Casey PA, Robin AL, Blachley T, et al. The most common barriers to glaucoma medication adherence: a cross-sectional survey. Ophthalmology. 2015;122(7):1308-1316. doi:10.1016/j. ophtha.2015.03.026

9. Tsai JC, McClure CA, Ramos SE, Schlundt DG, Pichert JW. Compliance barriers in glaucoma: a systematic classification. J Glaucoma. 2003;12(5):393-398. doi:10.1097/00061198200310000-00001

10. Sanchez FG, Mansberger SL, Newman-Casey PA. Predicting Adherence with the Glaucoma Treatment Compliance Assessment Tool. J Glaucoma. 2020;29(11):1017-1024. doi:10.1097/ IJG.0000000000001616

11. Peralta E, Muir KW, Rosdahl JA. Systematic review of knowledge assessments for glaucoma patients. Semin Ophthalmol. 2018;33 (3):377-388. doi:10.1080/08820538.2016.1247180
12. Okeke CO, Quigley HA, Jampel HD, et al. Interventions improve poor adherence with once daily glaucoma medications in electronically monitored patients. Ophthalmology. 2009;116(12):2286-2293. doi:10.1016/j.ophtha.2009.05.026

13. Sleath B, Blalock SJ, Carpenter DM, et al. Provider education about glaucoma and glaucoma medications during videotaped medical visits. J Ophthalmol. 2014;2014:1-7. doi:10.1155/2014/238939

14. Carpenter DM, Blalock SJ, Sayner R, et al. Communication predicts medication self-efficacy in glaucoma patients. Optom Vis Sci. 2016;93(7):731-737. doi:10.1097/OPX.0000000000000856

15. Gray TA, Fenerty C, Harper R, et al. Individualised patient care as an adjunct to standard care for promoting adherence to ocular hypotensive therapy: an exploratory randomised controlled trial. Eye. 2012;26(3):407-417. doi:10.1038/eye.2011.269

16. Carpenter DM, Tudor GE, Sayner R, et al. Exploring the influence of patient-provider communication on intraocular pressure in glaucoma patients. Patient Educ Couns. 2015;98(12):1558-1567. doi:10.1016/j. pec.2015.07.001

17. Newman-Casey PA, Musser JA, Niziol LM, et al. Integrating patient education into the glaucoma clinical encounter: a lean analysis. J Glaucoma. 2019;28(5):415-422. doi:10.1097/IJG.0000000000001192

18. Sleath B, Blalock SJ, Carpenter DM, et al. Ophthalmologist-patient communication, self-efficacy, and glaucoma medication adherence. Ophthalmology. 2015;122(4):748-754. doi:10.1016/j. ophtha.2014.11.001

19. Cate H, Bhattacharya D, Clark A, Fordham R, Holland R, Broadway DC. Improving adherence to glaucoma medication: a randomised controlled trial of a patient-centred intervention (The Norwich Adherence Glaucoma Study). BMC Ophthalmol. 2014;14:32. doi:10.1186/1471-2415-14-32

20. Newman-Casey PA, Niziol LM, Mackenzie CK, et al. Personalized behavior change program for glaucoma patients with poor adherence: a pilot interventional cohort study with a pre-post design. Pilot Feasibility Stud. 2018;4(1):1-13. doi:10.1186/s40814-018-0320-6

21. Morrison F, Shubina M, Turchin A. Lifestyle counseling in routine care and long-term glucose, blood pressure, and cholesterol control in patients with diabetes. Diabetes Care. 2012;35(2):334-341. doi:10.2337/dc11-1635

22. Boden G, Sargrad K, Homko C, Mozzoli M, Stein TP. Effect of a low-carbohydrate diet on appetite, blood glucose levels, and insulin resistance in obese patients with type 2 diabetes. Ann Intern Med. 2005;142(6):403-411. doi:10.7326/0003-4819-142-6-200503150-00006

23. Hughes TA, Gwynne JT, Switzer BR, Herbst C, White G. Effects of caloric restriction and weight loss on glycemic control, insulin release and resistance, and atherosclerotic risk in obese patients with type II diabetes mellitus. Am J Med. 1984;77(1):7-17. doi:10.1016/00029343(84)90429-7

24. The Trials of Hypertension Prevention Collaborative Research Group. Effects of weight loss and sodium reduction intervention on blood pressure and hypertension incidence in overweight people with high-normal blood pressure. The Trials of Hypertension Prevention, Phase II. Arch Intern Med. 1997;157(6):657-667.

25. Blumenthal JA, Babyak MA, Hinderliter A, et al. Effects of the DASH diet alone and in combination with exercise and weight loss on blood pressure and cardiovascular biomarkers in men and women with high blood pressure: the ENCORE study. Arch Intern Med. 2010;170(2):126-135. doi:10.1001/archinternmed.2009.470

26. Appel LJ, Champagne CM, Harsha DW, et al. Effects of comprehensive lifestyle modification on blood pressure control: main results of the PREMIER clinical trial. JAMA. 2003;289(16):2083-2093. doi:10.1001/jama.289.16.2083

27. Sacks FM, Svetkey LP, Vollmer WM, et al. Effects on blood pressure of reduced dietary sodium and the Dietary Approaches to Stop Hypertension (DASH) diet. DASH-Sodium Collaborative Research Group. $N$ Engl $J$ Med. 2001;344(1):3-10. doi:10.1056/ NEJM200101043440101 
28. Pasquale LR, Kang JH. Lifestyle, nutrition, and glaucoma. J Glaucoma. 2009;18(6):423-428. doi:10.1097/IJG.0b013e31818d3899

29. Hodapp E, Parrish RK, Anderson Douglas R. Clinical Decisions in Glaucoma. St. Louis, Mo.: Mosby; 1993.

30. Cohen S, Janicki-Deverts D. Who's stressed? Distributions of psychological stress in the United States in probability samples from 1983, 2006, and 2009. J Appl Soc Psychol. 2012;42(6):1320-1334. doi:10.1111/j.1559-1816.2012.00900.x

31. Harris PA, Taylor R, Thielke R, Payne J, Gonzalez N, Conde JG. Research electronic data capture (REDCap)-A metadata-driven methodology and workflow process for providing translational research informatics support. $J$ Biomed Inform. 2009;42(2):377-381. doi:10.1016/j.jbi.2008.08.010

32. Microsoft Office Excel 2007. Microsoft, Redmond, WA.

33. R Core Team (2014). R: A language and environment for statistical computing. R Foundation for StatisticalComputing, Vienna, Austria. Available from: http://www.R-project.org/.

34. Chang DS, Friedman DS, Frazier T, Plyler R, Boland MV. Development and validation of a predictive model for nonadherence with once-daily glaucoma medications. Ophthalmology. 2013;120 (7):1396-1402. doi:10.1016/j.ophtha.2013.01.002

35. Friedman DS, Hahn SR, Gelb L, et al. Doctor-patient communication, health-related beliefs, and adherence in glaucoma: results from the Glaucoma Adherence and Persistency Study. Ophthalmology. 2008;115(8):1320-1327.e3. doi:10.1016/j.ophtha.2007.11.023

36. Boland MV, Chang DS, Frazier T, Plyler R, Friedman DS. Electronic monitoring to assess adherence with once-daily glaucoma medications and risk factors for nonadherence: the Automated Dosing Reminder Study. JAMA Ophthalmol. 2014;132(7):838-844. doi:10.1001/jamaophthalmol.2014.856
37. Jayawant SS, Bhosle MJ, Anderson RT, Balkrishnan R. Depressive symptomatology, medication persistence, and associated healthcare costs in older adults with glaucoma. J Glaucoma. 2007;16 (6):513-520. doi:10.1097/IJG.0b013e31804a5ec6

38. Kang JH, Wu J, Cho E, et al. Contribution of the nurses' health study to the epidemiology of cataract, age-related macular degeneration, and glaucoma. Am J Public Health. 2016;106(9):1684-1689. doi:10.2105/AJPH.2016.303317

39. Perez CI, Singh K, Lin S. Relationship of lifestyle, exercise, and nutrition with glaucoma. Curr Opin Ophthalmol. 2019;30(2):82-88. doi:10.1097/ICU.0000000000000553

40. Hecht I, Achiron A, Man V, Burgansky-Eliash Z. Modifiable factors in the management of glaucoma: a systematic review of current evidence. Graefes Arch Clin Exp Ophthalmol. 2017;255 (4):789-796. doi:10.1007/s00417-016-3518-4

41. Kass MA, Meltzer DW, Gordon M, Cooper D, Goldberg J. Compliance with topical pilocarpine treatment. Am J Ophthalmol. 1986;101(5):515-523. doi:10.1016/0002-9394(86)90939-6

42. Lim MC, Watnik MR, Imson KR, Porter SM, Granier AM. Adherence to glaucoma medication. J Glaucoma. 2013;22 (6):439-446. doi:10.1097/ijg.0b013e31824cd0ae
Clinical Ophthalmology

\section{Publish your work in this journal}

Clinical Ophthalmology is an international, peer-reviewed journal covering all subspecialties within ophthalmology. Key topics include: Optometry; Visual science; Pharmacology and drug therapy in eye diseases; Basic Sciences; Primary and Secondary eye care; Patient Safety and Quality of Care Improvements. This journal is indexed on PubMed
Dovepress

Central and CAS, and is the official journal of The Society of Clinical Ophthalmology (SCO). The manuscript management system is completely online and includes a very quick and fair peer-review system, which is all easy to use. Visit http://www.dovepress.com/ testimonials.php to read real quotes from published authors. 